\title{
SENSOR BASED ACCIDENT MAPPING SYSTEM
}

\author{
Assi.Prof.Mali S.P. \\ Department of CSE \\ AITRC, Vita, Maharashtra, India \\ Mane Shalaka K. \\ Department of CSE \\ AITRC, Vita, Maharashtra, India
}

\author{
Jadhav Priyanka H. \\ Department of CSE \\ AITRC, Vita, Maharashtra, India \\ Ghodake Shital T. \\ Department of CSE \\ AITRC, Vita, Maharashtra, India
}

\begin{abstract}
Hundreds and thousands of vehicles are involved in the server accident every year worldwide. The place where accidents are more likely to happen include someplace where has few inhabitants or no camera surveillance such as highway and country trail. In this situation Sensor based accident mapping systems are valid device for increasing driver's safety by informing emergency calls.
\end{abstract}

\section{Keywords - GPS Module, Sensors, Raspberry pi}

\section{INTRODUCTION}

The Sensor based Accident mapping system is based on the Internet of things technology. Sensor Base Accident mapping system main aim is to give Security to all vehicles and drivers. This is improved security systems for vehicles. Sensor Based Accident mapping system is a web-based multiplatform accident reporting system with adequate functionality for tracking the accident location. It is mainly benefit for the companies which are based on transport system. Accident detection module includes GSM and GPS technology. The system can automatically detect a traffic accident occurrence, search for the spot and then send the basic information to Emergency Contacts, the time and circumstances in which a traffic accident takes place. GPS software is fitted in the vehicle will now start communicate with the satellite and get the latitude and longitude values and send the information to the centralized server.

Then the server will search the nearest hospital and send the accident information to the hospital. The hospital will then send their ambulance to the accident zone to rescue the injured people as soon as possible. The main objective of this System is to reduce the time required to report an accident and to determine its location more precisely. This will reduce the time required for the police and the emergency personnel to reach the accident location. The proposed idea will make the location identification automatic and hence will be more precise and take less time. Internet of things: With the electrification of the world around us, the IOT is a much profound term for the advancement where the billions of smart, connected technology would be making our life much easier, smarter and safer by "commanding and controlling" things. The creativity of this much hyped term is limitless with an astonishing potency to improve and make our life safer The things in the IOT could be a variety of million things.

\section{PROPOSED WORK CONVERTED TO CONCEPT-}

In this system Sensor Based Accident Mapping system are used for accident detection and Reporting system. When accident occurs, this system sends short message to mobile number via GSM modem. Message will give longitude and latitude values. From hense values location of accident can be determined. For this the user vehicle is fixed with an GSM Model that has a sensors along with Raspberry Pi. Whenever a user vehicle meets with any accident, the vibration sensor detects and gives its output. This output is then detected by the Raspberry Pi. GPS software is fitted in the vehicle will now start communicate with the satellite and get the latitude and longitude values and send the information to the centralized server



Fig.1. System Architecture

The Sensor based Accident mapping system is based on the Internet of things Technology. Sensor Based Accident mapping system main aim is to give Security to all 


\section{International Journal of Engineering Applied Sciences and Technology, 2019 \\ Vol. 3, Issue 10, ISSN No. 2455-2143, Pages 44-46 \\ Published Online February 2019 in IJEAST (http://www.ijeast.com)}

Vehicles and drivers. This is improved security systems for vehicles. Sensor Based Accident mapping system is a webbased multiplatform accident reporting system with adequate functionality for tracking the accident location. It is mainly benefit for the companies which are based on transport system Accident detection module includes GSM and GPS technology.



Fig.2. DFD 0



Fig.3. DFD 1

\section{FUTURE PROSPECT-}

The Sensor based Accident mapping system is based on the Internet of things Technology. Sensor Based Accident mapping system main aim is to give Security to all Vehicles and drivers. This is improved security systems for vehicles. Sensor Based Accident mapping system is a web-based multiplatform accident reporting system with adequate functionality for tracking the accident location. It is mainly benefit for the companies which are based on transport system. Accident detection module includes GSM and GPS technology. The system can automatically detect a traffic accident occurrence, search for the spot and then send the basic information to Emergency Contacts, the time and circumstances in which a traffic accident takes place. GPS software is fitted in the vehicle will now start communicate with the satellite and get the latitude and longitude values and send the information to the centralized server.

\section{EXPERIMENT AND RESULT}



(a)



(b)

Fig.4. (a).First Model,(b).Final Model 


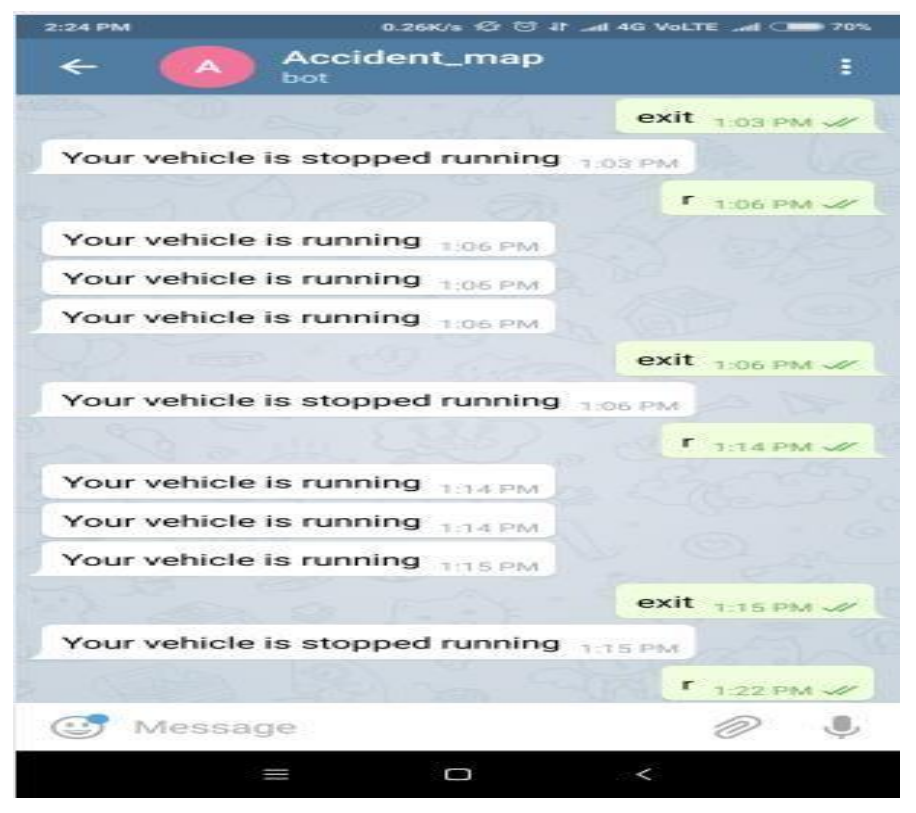

(c)

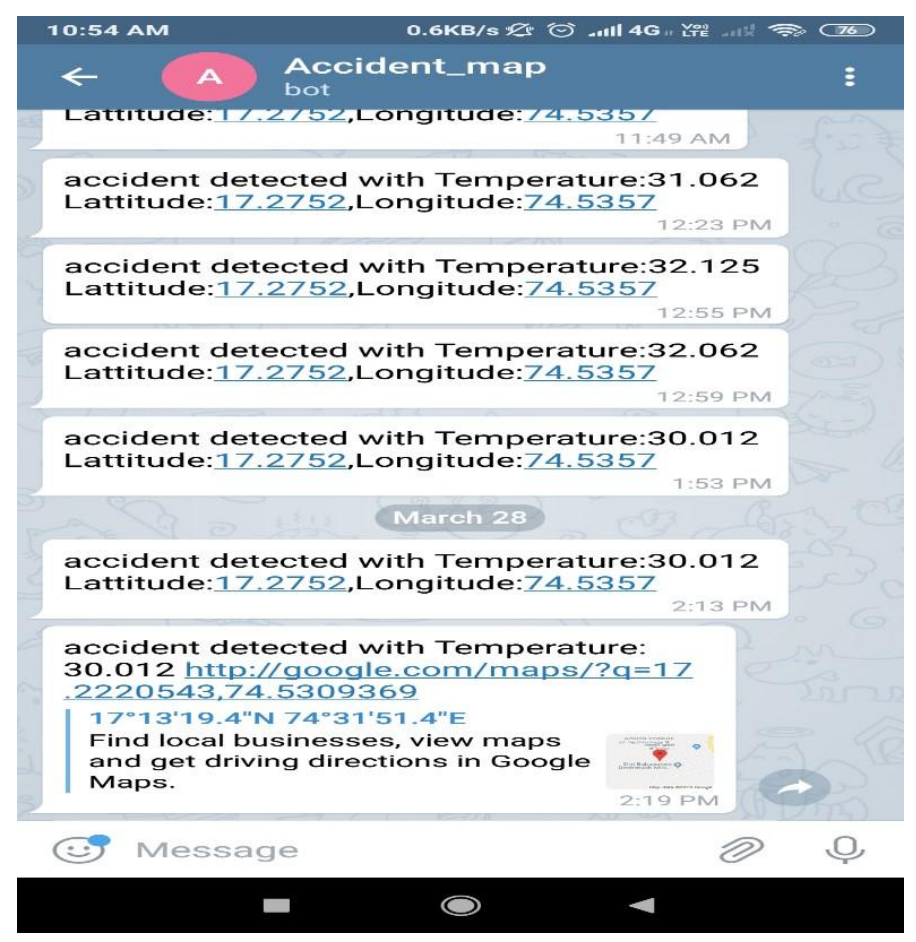

(d)

Fig.5.(c)First Result Snap,(d).Final Result Snap

\section{CONCLUSION}

This system consists of two main parts: the detection device and the server for report system. The Sensor based Accident mapping system is based on the Internet of things Technology .Sensor Based Accident mapping system main aim is to give Security to all vehicles and drivers. It is mainly benefit for the companies which are based on transport system. To reduce the time required for the emergency personnel to reach the accident location. Emergency service by hospitals or police is provided at the place of accident at required time. It protects the life of people.

\section{REFERENCE}

[1] F.Alkhateeb, (2010)"The Use of Location Based Services for Very Fast and Precise Accidents Reporting and Locating" Slam Al Maghayreh and Mohammad Tubist Faculty of Information Technology and Computer Science, International Conference on Intelligent Systems, Modeling and Simulation 2010 IEEE

[2] D.Acharya,V.Kumar,N. Garvin, A.Greco andG.M. Gaddis (2008), “A Sun SPOT based Automatic Vehicular

Accident Notification System”, (978-1-4244-2255-

5/08/\$25 C2008)

[3]. Guanpi Lai, Fei-Yue Wang”(2003) A New Safety Warning System Based on Implementation of Digital Vehicle/Highway Technology" 2003 IEEE

[4]. K..Megalingam, R.Nammily Nair, "Wireless Vehicular Accident Detection and Reporting System" M.Sai , A.Vishwa Prakhya, Vidyapeetham, Amritapuri, Clappana( P.O, Kollam-690525, Kerala, India ) 